\title{
Zenbakizko biskositateak eragindako soinu-eztandaren simulazioaren zailtasunak
}

\author{
(Difficulties of the sonic-boom simulation induced \\ by the numerical viscosity)
}

Alejandro Pozo Pazos

BCAM-Basque Center for Applied Mathematics. Alameda de Mazarredo 14, 48009 Bilbao

alejandropozo@gmail.com

Laburpena: Hegazkin supersonikoek eragindako soinu-eztandaren hedapena eremu hurbiletik lurreraino zehatz-mehatz simulatzea ez da erraza. Ereduaren denbora-tarte handietarako propietateak babesten dituzten zenbakizko metodoak behar dira. Artikulu honetan, soinu-eztandaren minimizazioarekin erlazionaturik dagoen optimizazio eta alderantzizko diseinu-problema ikertu dugu. Bereziki, bere soluzioaren hurbilketen eraginkortasuna mantentzeko gakoak ematen ditugu.

Hitz gakoak: Soinu-eztanda, denbora-tarte handiko portaera, biskositatea, zenbakizko metodoak.

\begin{abstract}
Simulating the propagation of the sonic-boom precisely from the near-field of a supersonic airplane down to the ground level is not easy. It requires numerical schemes that preserve the large-time properties of the model. In this article we deal with an optimization and inverse design problem related to the sonic-boom minimization. In particular, we emphasize the key points that need to be handled in order to keep the efficiency of the approximations of its solution.
\end{abstract}

Keywords: Sonic-boom, large-time behaviour, viscosity, numerical methods.

\section{SARRERA}

Azken mendean, konputazioaren aurrerakuntzari esker, gure ingurunean aurki ditzakegun hainbat fenomeno simulatzea eta iragartzea lortu dugu. Horien artean badira denbora luzean gertatzen diren eboluzio-ere- 
duak: sateliteen ibilbidea, tsunamien mugimendua, aldaketa klimatikoa... Normalean, ez da posible fenomeno horiek deskribatzen dituzten ekuazioen soluzio zehatzak lortzea. Beraz, horiek ahalik eta ondoen hurbiltzen dituzten metodoak garatu behar izan ditugu.

Zenbakizko analisi klasikoak ekuazio horiek hartu eta teknika ezberdinen bidez (diferentzia finituak, elementu finituak...), espazio eta denbora osoan soluzioa lortu ordez, zenbait puntutan baino ez du hurbilketa egiten. Puntuen arteko distantzia zenbat eta txikiagoa izan, orduan eta zehatzagoa izango da hurbilketa.

Baina, denbora-tartea handia denean, batzuetan sare diskretu horien tamaina txikia izatea ez dela nahikoa erakutsiko dugu artikulu honetan. Hemen laburtzen dugun tesi-lanean [1], hegazkin supersonikoek eragiten duten soinu-eztandaren hedapena hartu dugu, zenbakizko analisiaren ikuspuntutik denbora luzeak agerraraz ditzakeen zailtasunak erakusteko.

\section{SOINU-EZTANDAREN MINIMIZAZIOA}

Gizadiak betidanik izan du garraioak ahalik eta azkarren egiteko premia: antzinako gurdietatik hasita espazio-anezkara heldu arte. Airetik, lurretik edo uretatik bada ere, helmugara lehenbailehen heltzea da asmoa, baina, noski, era seguruan eta dirua xahutu barik. Esate baterako, oso ezaguna da Concorde hegazkin supersonikoaren kasua: Europa eta Estatu Batuetako kostaldeak hiru orduko bidaiaz lotzea lortu arren, istripuak eta arazo ekonomikoak zirela eta, bere erabilera eten egin zen.

XXI. mendearen hasieran, DARPA/NASA/Northrop-Grumman Shaped Sonic Boom Demonstrator (SSBD) programak [2] hegazkinaren forma eraldatuz soinu-eztanda leuntzea posible zela erakutsi zuen. Berrogeita hamar urtez hainbat ikertzailek teoria ugari ebatzi zituzten, baina SSBDa izan zen esperimentalki frogatzea lortu zuten lehen proiektua.

Izan ere, hegazkin supersonikoak izan dira XX. mendearen azken hamarkadetan aeronautika-ikerketen helburu nagusietako bat. Bereziki, aireontzi mota horrek eragiten duen soinu-eztandari aurre egitea oinarrizkoa dela argi geratu zen. Soinuaren abiadura gainditzean, hegazkin supersonikoek atmosferan presio perturbazioak sortzen dituzte, airearen lekualdatzeak eta euste aerodinamikoak eraginda. Energia akustiko itzela izanik, bai gizakiontzat, bai eraikinentzat oso kaltegarriak diren perturbazio horiek lurzorura heltzen dira, soinu-eztanda agerraraziz. Beraz, hori nolabait kontrolatzea da garraio zibil supersonikoak berriz garatu ahal izateko giltza [3].

Kostuak murrizteko erreminta nagusia zenbakizko analisian oinarritutako simulazio konputazionala da. Soinu-eztandaren hedapenaren eredutzat Burgersen ekuazio handitua (hemendik aurrera, ABE ingeleseko Augmen- 
ted Burgers Equation izenaren siglak jarraituz) hartu dugu [4, 5]. Honek efektu ez-linealak - adibidez, uhinaren makurtzea eta hedapen-abiadura aldakorra - ez ezik, lasaikuntza molekularra, izpi-hodien zabalketa eta atmosferaren geruzak ere kontuan hartzen ditu. Ekuazioa hurrengoa da:

$$
\left\{\begin{array}{l}
\frac{\partial P}{\partial \sigma}=P \frac{\partial P}{\partial \tau}+\frac{1}{\Gamma} \frac{\partial^{2} P}{\partial \tau^{2}}+\sum_{v} C_{v} \frac{\frac{\partial^{2} P}{\partial \tau^{2}}}{1+\theta_{v} \frac{\partial}{\partial \tau}}-\frac{1}{2 G} \frac{\partial G}{\partial \sigma} P+\frac{1}{2 \rho_{0} c_{0}} \frac{\partial\left(\rho_{0} c_{0}\right)}{\partial \sigma} P, \\
P(0, \tau)=P_{0}(\tau),
\end{array}\right.
$$

non $P=P(\sigma, \tau)$ dimentsiorik gabeko presio-banaketaren perturbazioa den. Hedapenaren distantzia $(\sigma)$ eta perturbazioaren iraupena $(\tau)$ ere dimentsiorik gabekoak dira. Lasaikuntza molekularrei dagokien baturan agertzen den eragilea horrela definiturik dago:

$$
\frac{\theta_{v}}{1+\theta_{v} \frac{\partial}{\partial \tau}} f(\tau)=\int_{-\infty}^{\tau} e^{(\xi-\tau) / \theta_{v}} f(\xi) d \xi .
$$

$G$ funtzioak izpi-hodiaren azalera adierazten du. Atmosferako baldintzak hurrengo parametroez ezarrita daude: $\varrho_{0}$ dentsitateaz, $c_{0}$ soinuaren abiaduraz, $\Gamma$ termo-biskositate parametroaz eta lasaikuntza mota bakoitzeko (normalean, oxigenorako eta nitrogenorako) dimentsiorik gabeko $\theta_{v}$ lasaikuntza-denborez eta $C_{v}$ dispertsio-parametroez. Eredu osoaren froga teorikoa R.O. Cleveland-en doktorego-tesian [6] aurki daiteke.

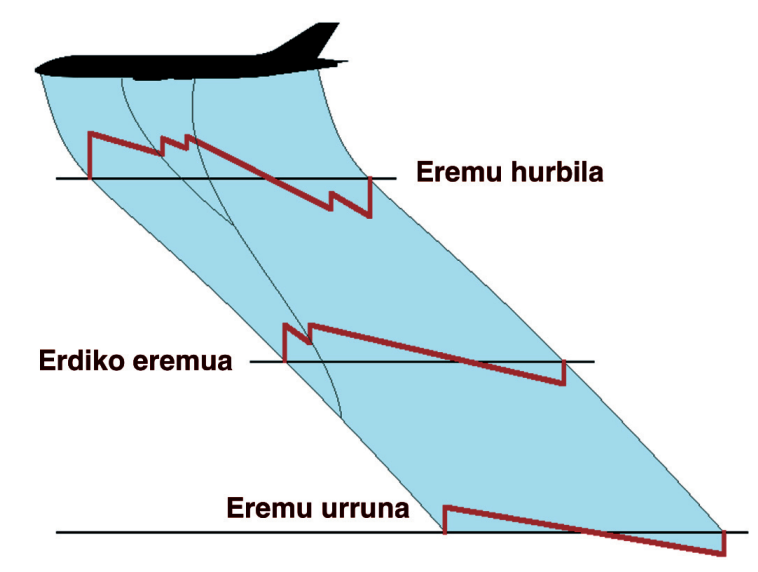

1. irudia. Hegazkinaren eremu hurbileko soinu-sinaduraren bilakaera, (1) ABE ekuazioaren arabera. 
Esparru honetan, soinu-eztandaren minimizazioaren problema (ikusi 1. irudia) honetan datza: eremu urrunean edo lurzoruan lortu nahi den $P^{*}$ sinadura eta hedapenaren $\Sigma$ iraupena - hegaldiaren altitudearekin erlazionaturik dagoena - emanik, $P^{*}$ hobeto erreproduzitzen duen hegazkinaren eremu hurbileko $P_{0}$ sinadura berreskuratu. Hori formulatzeko ohiko era karratu txikienen metodoaren bidez da [5], hurrengo funtzionala erabiliz:

$$
\min _{P_{0} \in \Omega} \frac{1}{2} \int_{\mathbb{R}}\left(P\left(\sum, \tau\right)-P^{*}(\tau)\right)^{2} d \tau, \text { non } P(1) \text { ekuazioaren soluzioa den. }
$$

$\Omega$ onargarriak diren eremu hurbileko sinaduren multzoa da (adibidez, hegazkinaren geometriak ezarritako diseinu-aldagaiek definiturikoa [5, 7]).

Soinu-eztandaren minimizazio-problema horretan denbora-eskalak oso ezberdinak dira: presioaren perturbazioa segundo erdi baino gutxiago batean gertatzen den bitartean, uhinaren hedapenak ia minutu oso bat iraun dezake, hegaldiaren baldintzen arabera [4]. Horrek tratamendu konputazionala zaildu egiten du eta, beraz, zenbakizko eskemen denbora-tarte luzeetan daukaten portaera aztertzea ezinbestekoa da.

\section{BURGERSEN EKUAZIOAREN SOLUZIOA}

Burgersen ekuazio handitua Burgersen ekuazio klasikoan [8] oinarrituta dago. Ekuazio mota hori anplitude mugatuko uhinen zabaltzea imitatzeko erabili ohi da. Hainbat egilek lortutako orokortzeetan ingurune barreiatzaileetan gertatzen diren beste zenbait efektu izan dituzte kontuan: zabalpen geometrikoa [9], ingurune heterogeneoak [10, 11], lasaikuntzaprozesuak [12]... (1) ABE ekuazioak fenomeno horiek guztiak kontuan hartzen ditu soinu-eztandaren hedapena modelatzeko.

Soluzioen ezaugarriak eta portaera bereziak aztertzeko orduan, ostera, hurrengo eredua hartzen da abiapuntu gisa:

$$
\left\{\begin{array}{l}
u_{t}^{v}+\left(\frac{\left(u^{v}\right)^{2}}{2}\right)_{x}=v u_{x x}^{v}, \quad x \in \mathbb{R}, \quad t>0, \\
u^{v}(0, x)=u_{0}(x), \quad x \in \mathbb{R},
\end{array}\right.
$$

non $v$ ingurunearen biskositatearen neurria den. Airearena oso txikia izanik, askotan $v=0$ hartzen da; baina aurrerago ikusiko dugun bezala, horrek soluzioen denbora luzeko portaera guztiz aldatzen du.

Bi kasuen arteko ezberdintasun nagusia soluzioen jarraitutasuna da. Hasierako $u_{0}$ datuak jauziren bat badauka ere, $v>0$ biskositatearen efektu erregularizatzaileari esker, berehala desagertuko da. Baldin $v=0$ bada, os- 

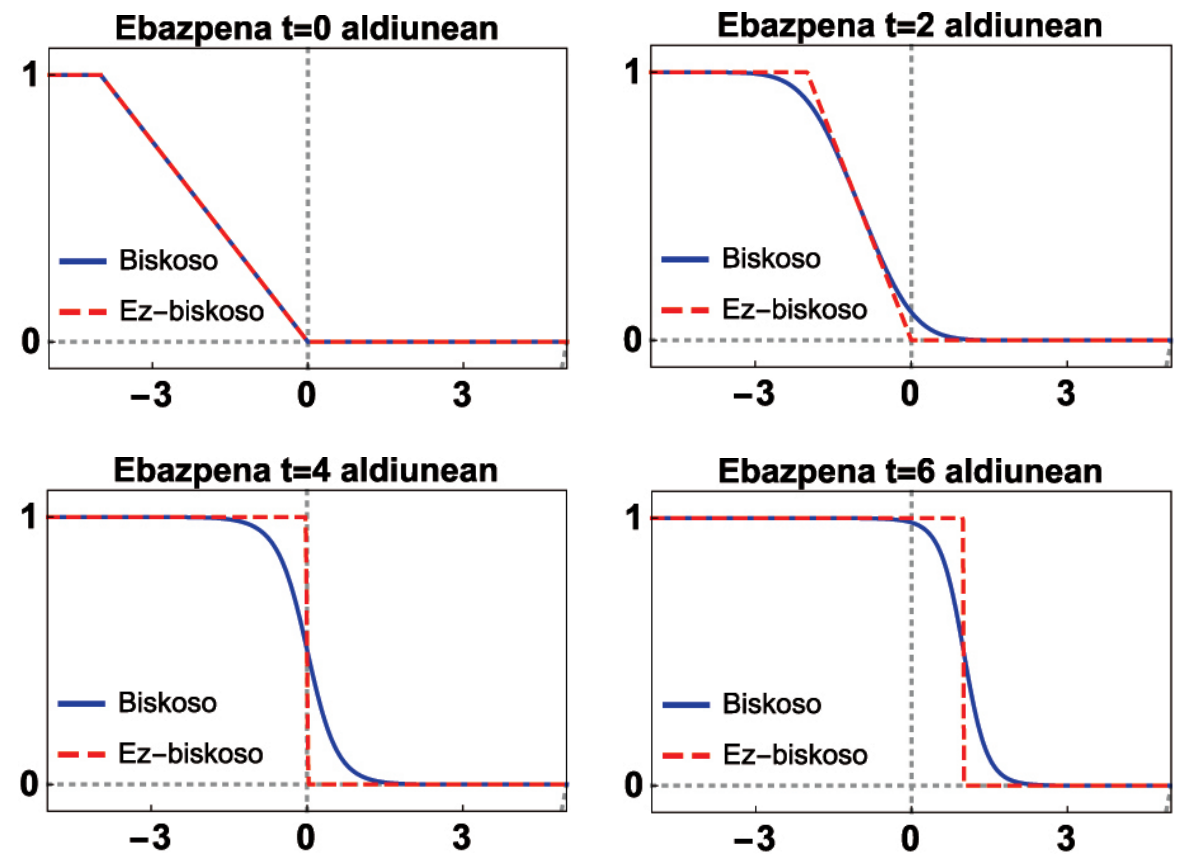

2. irudia. Jauziak biskositaterik ez dagoenean agertzen dira soilik (gorriz, $t=4$ tik aurrera). Izan ere, talka-uhinek $\sqrt{v}$-ko lodiera dute.

tera, talka-uhinak agertuko dira lehenago edo beranduago hasierako datuak deribatu negatiboa duen punturik baldin badu (ikusi 2. irudia).

Fenomeno horrek, Burgersen ekuazioa hurbiltzeko zenbakizko metodoak garatzeko orduan, zailtasun handiak sortzen ditu. Soluzioak leunak direnean, diferentzia finitu klasikoak ondo dabiltza, baina etenak hurbiltzean huts egiten dute. Are gehiago, $v$ oso txikia denean ere agertuko dira arazo horiek, oso malda handiko guneak azaltzen baitira.

Oztopo hori salbuestearren, bolumen finituen metodoek (adibidez, begira $[13,14])$ eremu espaziala gelaxkatan banatu eta horietan soluzio jarraituak duen batez besteko balioa hurbiltzen dute. Gakoa gune horien arteko fluxua zehazten duen zenbakizko fluxu dezentea definitzean datza. Demagun $\Delta x>0$ gelaxka-tamaina eta $\Delta t>0$ denbora-pausoa ditugula. Orduan, $u^{v}(4)$ ekuazioaren soluzioa izanik:

$$
u_{j}^{n} \approx u^{v}(t, x), \text { non } n \Delta t \leq t<(n+1) \Delta t \quad \text { eta } \quad\left(j-\frac{1}{2}\right) \Delta x \leq x<\left(j+\frac{1}{2}\right) \Delta x
$$


Hurbilketa hori kalkulatzeko, hurrengo eskema erabiliko dugu:

$$
\left\{\begin{array}{l}
\frac{u_{j}^{n+1}-u_{j}^{n}}{\Delta t}+\frac{g\left(u_{j}^{n}, u_{j+1}^{n}\right)-g\left(u_{j-1}^{n}, u_{j}^{n}\right)}{\Delta x}=v \frac{u_{j-1}^{n}-2 u_{j}^{n}+u_{j+1}^{n}}{\Delta x^{2}}, j \in \mathbb{Z}, \quad n>0, \\
u_{j}^{0}=\frac{1}{\Delta x} \int_{x_{j}-\Delta x / 2}^{x_{j}+\Delta x / 2} u_{0}(z) d z, \quad j \in \mathbb{Z} .
\end{array}\right.
$$

Hemen $g$ zenbakizko fluxua da, $f(v)=v^{2} / 2$ fluxu jarraituaren hurbilketa. Artikulu honetan, bi eredu aztertuko ditugu:

- Engquist-Osher (EO): $g(v, w)=\frac{f(v)+f(w)}{2}-\frac{1}{2} \int_{v}^{w}\left|f^{\prime}(z)\right| d z$.

- Lax-Friedrich Eraldatua (MLF): $g(v, w)=\frac{f(v)+f(w)}{2}-\frac{\Delta x}{\Delta t} \frac{w-v}{4}$.

Lehen aipatu dugun bezala, talka-uhinak edo malda handiko guneak ager daitezke soluzioetan. Fenomeno hori ondo kudeatzeko, bolumen finituen metodoek zenbakizko biskositatea erabiltzen dute. (5) hurrengo eran berridatz dezakegu:

$$
\frac{u_{j}^{n+1}-u_{j}^{n}}{\Delta t}+\frac{f\left(u_{j+1}^{n}\right)-f\left(u_{j-1}^{n}\right)}{2 \Delta x}=\left(R\left(u_{j}^{n}, u_{j+1}^{n}\right)-R\left(u_{j-1}^{n}, u_{j}^{n}\right)\right)+v \frac{u_{j-1}^{n}-2 u_{j}^{n}+u_{j+1}^{n}}{\Delta x^{2}} .
$$

Eskuineko gai berri horrek, $v$ biskositate fisikoaren antzera, jauziak leuntzen ditu. Baina, hurrengo atalean ikusiko dugun moduan, abantaila dirudien hori oztopo handia bihur daiteke denbora-tarte luzeko simulazioetan.

Kontuan izan behar dugu Burgersen ekuazio handituaren kasuan fluxua alderantzizkoa dela; hau da, $\tilde{f}(v)=-v^{2} / 2$. Hala eta guztiz ere, bai denbora luzeko portaerari, bai zenbakizko eskemei dagokienez, ondorioak guztiz berdintsuak dira. Izan ere, Burgersen ekuazio klasikoan $\tilde{x}=-x$ algadai aldaketa eginez gero, soinu-eztandaren ekuazioaren fluxua agertzen da, gai ez-lineala eskuineko atalera pasatuz. Hortaz, 6. ataleko 9. irudian agertzen den $\mathrm{N}$-uhina beste noranzkoan doa.

Amaitzeko, (2) eragile ez-lokalaren diskretizazioa ere kontu handiz egitea nahitaezkoa dela aipatu beharra dago. Horretarako, hurrengo ekuazioa ere ikertu dugu: 


$$
\left\{\begin{array}{l}
u_{t}=\left(\frac{u^{2}}{2}\right)_{x}+u_{x x}+K * u_{x x}, \quad x \in \mathbb{R}, \quad t>0, \\
u^{v}(0, x)=u_{0}(x), \quad x \in \mathbb{R},
\end{array}\right.
$$

non $*$ espazioan konboluzioa den eta

$$
K(z)= \begin{cases}e^{-z}, & z>0 \\ 0, & z \leq 0\end{cases}
$$

Bertan, ia gai guztien zenbakizko hurbilketa aurreko Burgersen ekuazioan bezala egin daiteke. Gelditzen den $K * u_{x x}$ gaiaren kasurako

$$
\sum_{m=1}^{N} \omega_{m}\left(u_{j-m}-u_{j}+m\left(u_{j+1}-u_{j}\right)\right)
$$

diskretizazioa aukeratu dugu [15], non

$$
\omega_{m}=e^{-m \Delta x}\left(e^{\Delta x}-1\right), \quad m=1, \ldots, N,
$$

eta $N \in \mathrm{N}$ zenbakiak ( $\Delta x$-ekiko dependentzia duenak) integralaren koadratura formularen nodo kopurua adierazten duen. Metodo hau

$$
K * u_{x x}=u_{x}-u+K * u
$$

berdintzan oinarrituta dago eta, hurrengo atalean ikusiko dugunez, soluzioaren garraio ezegokia eragotziko du.

\section{DENBORA-TARTE LUZEKO DINAMIKA}

Soinu-eztandaren antzeko fenomenoak simulatzeko orduan, zenbakizko metodoen konbergentzia klasikoa ez da nahikoa. Euren oinarri teorikoa parametro txikiak erabiltzean datza: sare fin bat, amaiera-denbora txikia... Baina urrunago ailegatu behar dugunean, metodoen beste ezaugarri batzuk ikertu beharra dago, hurbilketen erroreak anplifikatzen baitira. Gure kasuan, denbora luzeko portaera egokia mantentzea ezinbestekoa da. Ikuspuntu horretatik, (1) ekuazioaren bi gaitan zentratu gara: gai ez-linealean eta eragile ez-lokalean. 


\subsection{Gai ez-lineala}

Burgersen ekuazioaren soluzioek, bai kasu biskosokoek, bai ez-biskosokoek, denbora-tarte luzeko portaera berezia dute: hasierako $u_{0}$ datua edonolakoa dela ere (integragarria izan behar du soilik), soluzio guztiek itxura berdina lortuko dute denbora-tarte nahiko handia igaro ondoren.

Izan ere, $t \rightarrow \infty$ heinean, kasu ez-biskosoko soluzioek $\mathrm{N}$-uhin antzeko forma garatzen dute [16], hurrengo bi funtzioak konstante mantenduz:

$$
p(t):=-\min _{x \in \mathbb{R}} \int_{-\infty}^{x} u^{v}(t, z) d z \quad \text { eta } \quad q(t):=\max _{x \in \mathbb{R}} \int_{x}^{\infty} u^{v}(t, z) d z, \quad \forall t>0 .
$$

Hau da, $v=0$ bada, $p(t)=p(0)$ eta $q(t)=q(0), t>0$ guztietarako.

Kasu biskosoko soluzioek antzeko portaera dute hasiera batean ( $v$ zenbat eta txikiagoa izan, orduan eta luzaroago iraungo du [17]), baina azkenik Gaussen kurbaren itxura duen uhinerantz jotzen dute beti. Kasu honetan, parametro bat baino ez da konstante mantentzen:

$$
m(t):=\int_{-\infty}^{\infty} u^{v}(t, x) d x
$$

$v>0$ bada, orduan $m(t)=m(0), t>0$ guztietarako (izan ere, hau kasu ez-biskosoan ere egia da). Baina $p(0) \geq q(0)$ bada, orduan $q(t) \rightarrow 0$ eta $p(t) \rightarrow m(0)$ (alderantziz, $p(0) \leq q(0)$ bada). Hasierako datuak integragarriak izanik, lehenago edo beranduago soluzioek 3 . irudiko uhinen antza garatzen dute beti. Jokaera horiek hurrengo bi limiteen emaitza ezberdinak izatea eragiten dute:

$$
\lim _{t \rightarrow \infty} \lim _{v \rightarrow 0} u^{v}(t, x) \quad \text { eta } \quad \lim _{v \rightarrow 0} \lim _{t \rightarrow \infty} u^{v}(t, x) .
$$

Lehenengoa kurba urdinaren antzekoa izango da eta bigarrena, ostera, kurba gorria bezalakoa.

Baina bitxiagoa da zenbakizko soluzioen portaera. Defini dezagun $u^{\Delta}$ zatikako funtzioa:

$$
u^{\Delta}(t, x)=u_{j}^{n}, \quad n \Delta t \leq t<(n+1) \Delta t \quad \text { eta } \quad\left(j-\frac{1}{2}\right) \Delta x \leq x<\left(j+\frac{1}{2}\right) \Delta x .
$$

Noski, $\Delta x \rightarrow 0$ eta $\Delta t \rightarrow 0$ heinean, $u^{\Delta} \rightarrow u^{\nu}$; hau da, zenbat eta txikiagoak izan sarearen parametroak, orduan eta zehatzagoa izango da hurbilketa. Baina konbergentzia klasikoak ez ditu eskemak bereizten: bai (6), bai (7) 
metodoez lortutako hurbilketek (4) soluziorantz joko dute sarea fintzen den heinean, baina denbora-tarte handiko jokaerak ez du zertan berdina izan:

$$
\lim _{\substack{t \rightarrow \infty \\ \Delta x \rightarrow 0 \\ \Delta t \rightarrow 0}} u^{\Delta}(t, x) ? \lim _{\substack{\Delta x \rightarrow 0 \\ \Delta t \rightarrow 0}} \lim _{t \rightarrow \infty} u^{\Delta}(t, x) .
$$

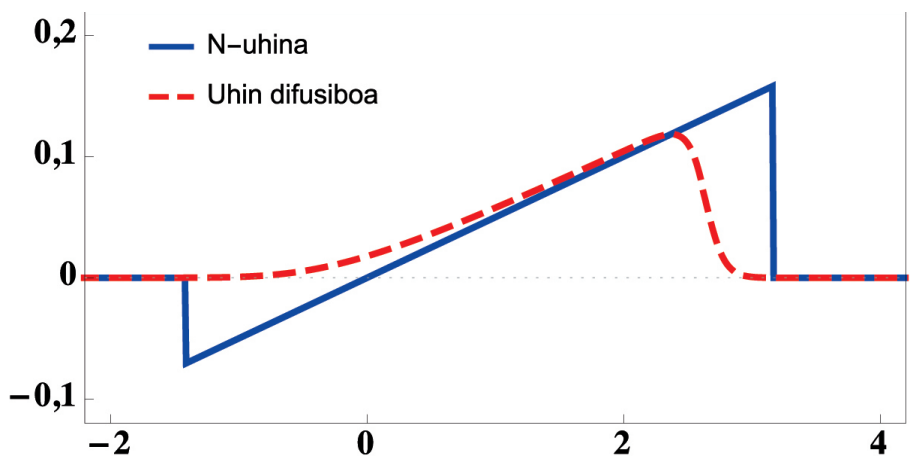

3. irudia. $v>0$ kasuan (gorriz) eta $v=0$ kasuan (urdinez) agertzen diren profil asintotikoak. Hemengo hasierako daturako $m(0)=0,15, p(0)=0,05$ eta $q(0)=0,2$ hartu ditugu .
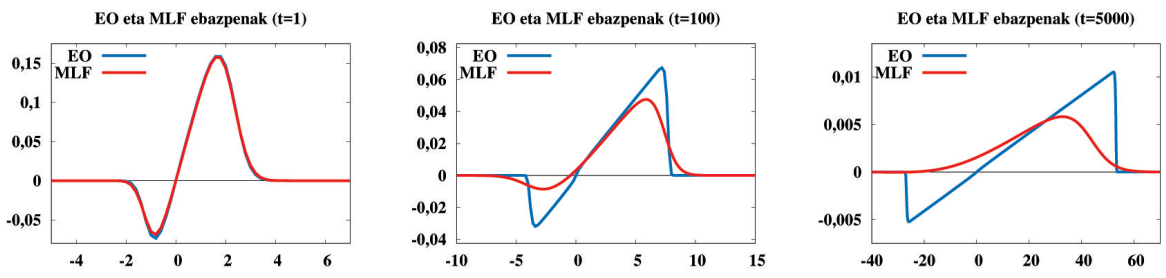

4. irudia. Hasiera batean $(t=1)$, bi eskemek lortzen dute hurbilketa ona. Denbora-tarte ertainean $(t=50)$, MLF parte negatiboa galtzen hasten da. Azkenik, denbora luzean, MLF metodoak N-uhina guztiz galtzen du; EOk, ordea, mantendu egiten du.

Horrek garrantzi handia dauka $v$ txikia hartzen dugunean, are gehiago $v=0$ kasuan. Orduan, (8) horrela geratzen da:

$$
\frac{u_{j}^{n+1}-u_{n}^{j}}{\Delta t}+\frac{f\left(u_{j+1}^{n}\right)-f\left(u_{j-1}^{n}\right)}{2 \Delta x}=R\left(u_{j}^{n}, u_{j+1}^{n}\right)-R\left(u_{j-1}^{n}, u_{j}^{n}\right) .
$$

Gure emaitzen arabera, eskuineko zenbakizko biskositateak portaera ezberdina hartuko du $R$ funtzioaren homogeneotasun graduaren arabera. De- 
magun edozein $\mu>0$ zenbakirako $\alpha \in \mathrm{R}$ existitzen dela hurrengo hau betez:

$$
R(\mu v, \mu w)=\mu^{\alpha} R(v, w) .
$$

$\alpha=2$ kasuan (adibidez, (6) eskema) zenbakizko biskositatearen denbora luzeko eragina desagertuko da, (12) berdintza betez. $\alpha=1$ kasuan (adibidez, (7) metodoa), ordea, $\Delta x^{2} / \Delta t$ antzeko zenbakizko biskositatearen eraginagatik, soluzio jarraituaren denbora luzeko portaera deuseztatuko da [18]. 4. irudian ikus daitekeenez, EO metodoak N-uhina mantentzen duen bitartean, MLFek berehala galtzen du soluzioaren parte negatiboa. $v>0$ kasuan arazo berbera aurkituko dugu MLF erabiltzean, $\Delta x^{2} / \Delta t$-ren balioa $\nu$-rena baino askoz txikiagoa ez bada.

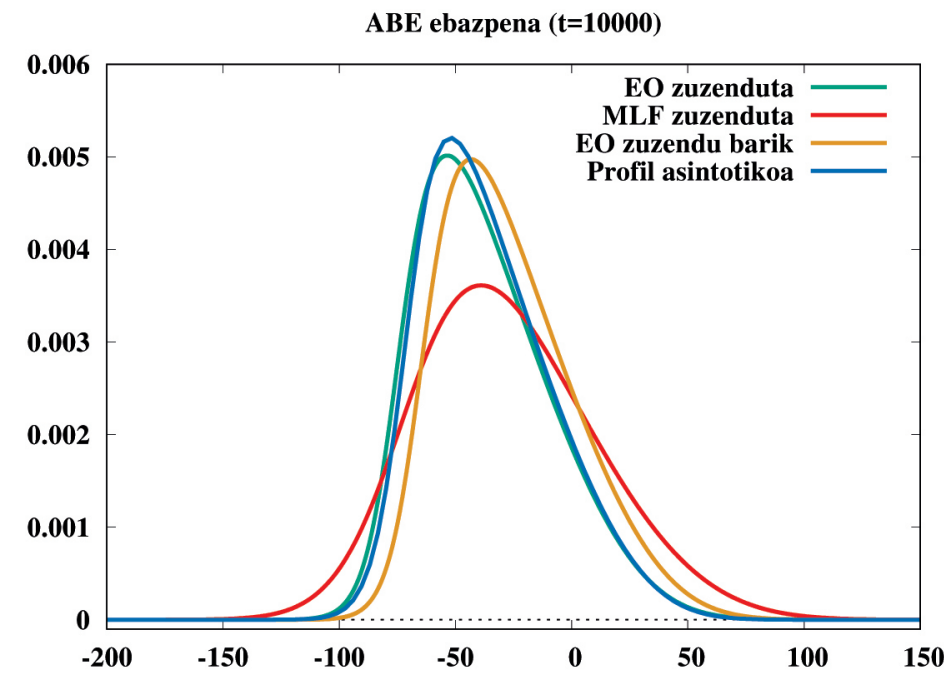

5. irudia. (9) ekuazioaren soluzioa $t=10.000$ unean. Zuzentzefaktoreak erabiliz, EO (berdez) eta MLF (gorriz), eta koefizienterik gabeko EO (laranjaz) metodoekin lortutako hurbilketak, profila asintotikoarekin (urdinez) konparaturik.

\subsection{Eragile ez-lokala}

Gai ez-linealaren influentzia maila ez duen arren, eragile ez-lokalaren diskretizazioak ere denbora luzeko portaera anomaloa eragin dezake. Hori kontrolatzeko, lehenik eta behin, $K * u_{x x}$ gaiaren portaera asintotikoa aurkitzeko beharra dago. Horretarako, aurreko atalean aipatu dugunez, oso lagungarria da (11) identitatea. Estimazio egokien bidez, $t \rightarrow \infty$ heinean 
$K * u_{x x}$ eta $u_{x x}$ portaera bera dutela froga daiteke [15]. Beraz, diskretizazioak hori mantendu behar du.

Guk aukeratutako (10) eskema berrantolatuz,

$$
\left(\Delta x \sum_{m=1}^{N} m \omega_{m}\right) \frac{u_{j+1}-u_{j}}{\Delta x}-\left(\sum_{m=1}^{N} \omega_{m}\right) u_{j}+\sum_{m=1}^{N} \omega_{m} u_{j-m},
$$

argi geratzen da $u_{x}-u+K * u$ adierazpenaren jatorria. Baina kontuan izan lehenengo bi gaiek konstante ezberdin bat dutela aurrean. Izan ere, bi koefiziente horiei esker, denbora luzeko portaeran ez da garraiorik agertzen soluzioan, 5. irudian ikus dezakegunez.

Bertan, EO zenbakizko fluxua eta guk proposatutako gai ez-lokalaren diskretizazioa erabiliz, (9) ekuazioaren soluzioaren hurbilketa (berdez) eta denbora luzeko profil asintotikoa (urdinez) oso antzekoak direla argi geratzen da. Zuzentze-faktorerik erabili ezean (laranja-kolorekoa), ostera, eskuineranzko desplazamendua agertzen da ereduan. Noski, aurretik genekien bezala, MLF erabiliz (gorriz), soberako biskositateak soluzioa zabaldu egiten du, zuzentze-faktorea erabili arren.

\section{BISKOSITATEAREN ERAGINA OPTIMIZAZIOAN}

Zenbakizko biskositatearen eragina denbora luzeko portaeran larria bada ere, are gehiago (3)-ren antzeko optimizazio-problema bat ebazteko orduan. Hurrengo ereduetan ikusiko dugunaren arabera, ez dugu denboratarte handiegirik hartu behar fenomeno arraroak antzemateko.
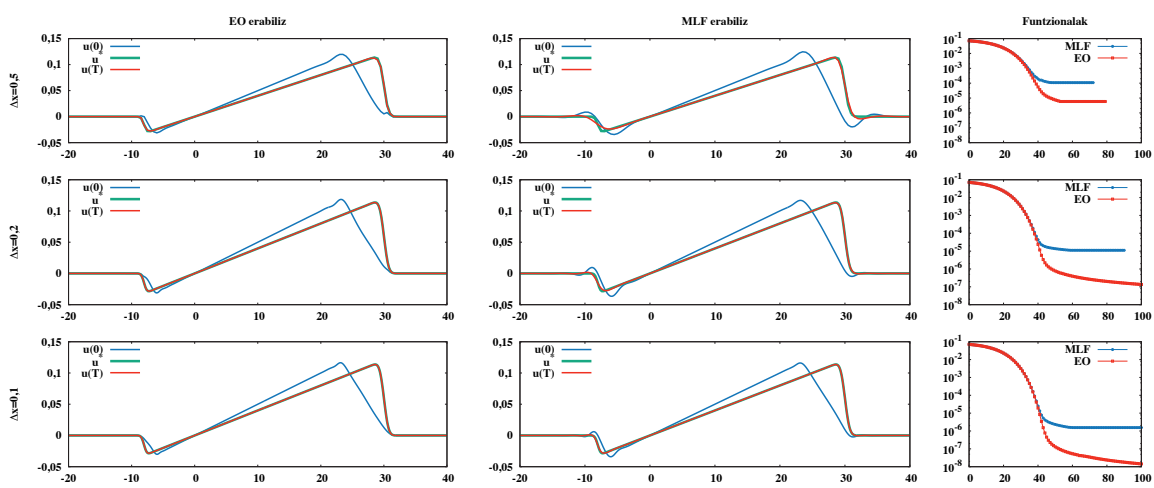

6. irudia. Lehenengo bi zutabeetan, EO (ezkerrean) eta MLF erabiliz lortutako optimizazio-problemaren soluzioak eta, eskuinaldean, funtzionalen bilakaera. Goitik behera, $\Delta x=0,5, \Delta x=0,2$ eta $\Delta x=0,1$. 
Izatez, eremu urruneko profila emanda, ekuazioa atzerantz ebazten datza problema. Berriz ere, bi oztopo nagusi kudeatu behar dira [19]: alde batetik, talka-uhinen agerraldiak gorabeherak sar ditzake optimizazio-prozesuan eta, beste aldetik, hori ekiditeko zenbakizko biskositateak denbora-itzulezintasuna sortzen du. Gainera, denbora-tarte luzeak maneiatzeak zailtasunak gaizkiagotzen ditu. Osagai horiei guztiei aurre egiteko konponbideen arteko oreka bilatzea ezinbestekoa da.

Optimizazio-problema hori kontrol optimoaren ikuspuntutik formulaturik dago eta, karratu txikienen metodoari jarraituz, gradiente jaiste-metodo iteratiboak dira zabalduenak. Horiek hasierako abiapuntu bat hartu eta, (3) funtzionalaren gradientearen hurbilketen bidez, soluziorantz konbergitzen duen segida eraikitzen dute. Gure kasuan, adjuntuaren metodoan oinarrituriko metodoa aukeratu dugu, baina aipatutako dikotomia beste zenbakizko tresna batzuetara zabal daiteke.

Hori guztia argi geratzearren, (4) hartu eta etenak dituzten soluzioak saihestu ditugu, optimizazio-prozesuan duten inpaktua murrizteko. Alde batetik, zenbakizko biskositate gehiegi erabiltzen ez duten metodoak aukeratu behar direla erakusten dugu. 6. irudian EO erabiliz helburua askoz hobeto hurbiltzen dela ikus daiteke. Izan ere, MLF metodoak denbora-itzulezinak diren arazoen berezko oszilazioak agerrarazten ditu. Nolanahi ere, bi kasuetan sarea finduz (zenbakizko eskemaren egonkortasun baldintzak betez), geroz eta hurbilketa hobea lortzen da.

Beste aldetik, jaiste-metodoaren pausoaren tamaina ere kontuz aukeratu behar dugu. Malda handiko guneak ager daitezkeenean, pauso luzeak hartzea ez da hautabide ona, behin horiek ageriz gero, oso zaila baita kokapena mugitzea. Prozesu iteratiboaren hasieran funtzionalaren jaitsiera handiagoa izango bada ere, berehala gera daiteke (ikusi 7. eta 8. irudiak).

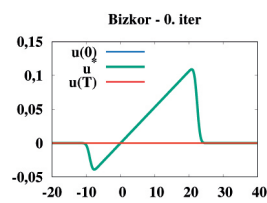

Poliki - 0. iter

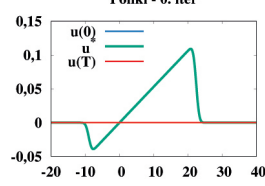

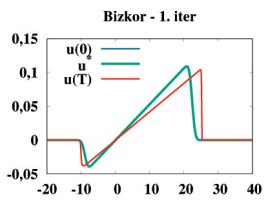

Poliki - 1. iter

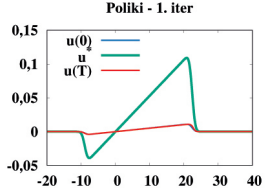

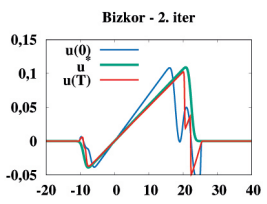

Poliki - 2. iter

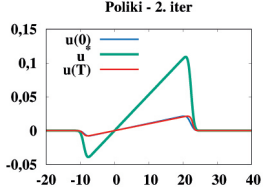

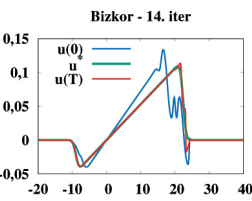

Poliki - 14. iter

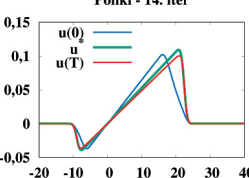

7. irudia. Iterazio-prozesuaren lehenengo urratsen ostean lortutako hurbilketak: goian pauso handiak emanez eta behean, txikiak. 14. iterazioan funtzionalak antzeko balioa du, baina hortik aurrera portaera desberdina izango dute (ikusi 8 . irudia). 


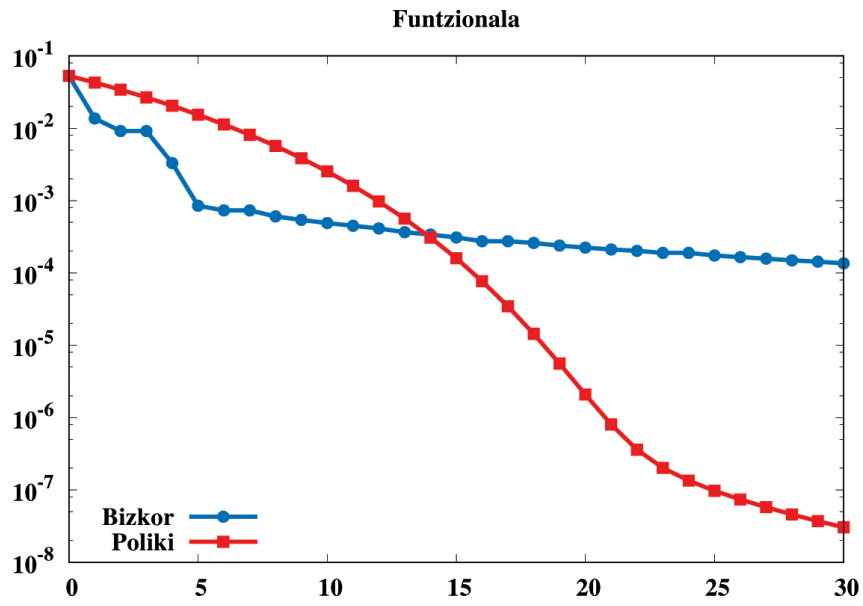

8. irudia. Pauso handiak emanez, hasierako jaitsiera handiagoa da. Baina bosgarren iteraziotik aurrera, beherakada moteldu egiten da. Pauso txikiez, ordea, konbergentzia hobea lortzen da.

\section{SOINU-EZTANDAREN APLIKAZIOA}

Amaitzeko, aurreko ataletan ikertutako zenbakizko zailtasunak kontuan izanik, soinu-eztandaren simulazio bat laburki aurkeztuko dugu (xehetasunetarako, begira [20]). Lehenik, eremu urruneko sinadura bat kalkulatu dugu (gorriz 9. irudian), 1. taulako datuak hartuz.

ABE ekuazioaren parametroei dagokienez, $\Gamma=8 \times 10^{6}$ hartu dugu. Lasaikuntza-parametroak 2. taulan agertzen dira. 10. irudian atmosferaren dentsitatea eta soinuaren abiadura erakusten ditugu. Azkenik, izpi-hodi zilindrikoa aukeratu dugu eta, beraz, $G_{\sigma} / G=1 /(2 \sigma)$. Balio guztiak $[4,5,6]-$ tik hartu ditugu.
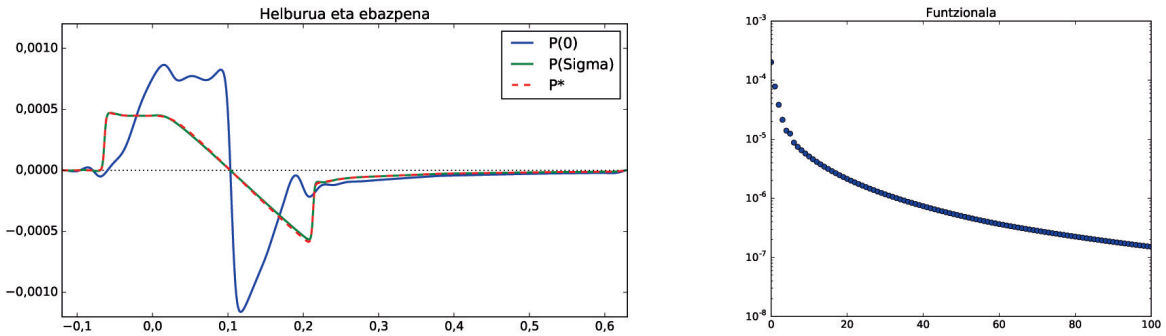

9. irudia. Ezkerraldean, eremu urruneko soinu-sinadura emanda (gorriz), hobeto hurbiltzen duen hasierako datua (urdinez) eta horrek ematen duen sinadura (berdez). Eskuinaldean, funtzionalaren bilakaera. 
1. taula. Optimizazio-problemaren helburua kalkulatzeko hartu ditugun parametroak.

Mach zenbakia, $M$

Hegazkinaren luzera, $L \quad 91,5 \mathrm{~m}$

Hegaldiaren altitudea, $z \quad 18.288 \mathrm{~m}$

Hegazkinetik eremu hurbilerako distantzia, $r=2 L \quad 183 \mathrm{~m}$

2. taula. Lasaikuntza molekularren parametroen balioak.

\begin{tabular}{ccc}
\hline & Oxigenoa & Nitrogenoa \\
\hline$C_{v}$ & $1,7 \times 10^{-5}$ & $1,2 \times 10^{-4}$ \\
$\theta_{v}$ & $4,6 \times 10^{-8}$ & $1,6 \times 10^{-6}$ \\
\hline
\end{tabular}
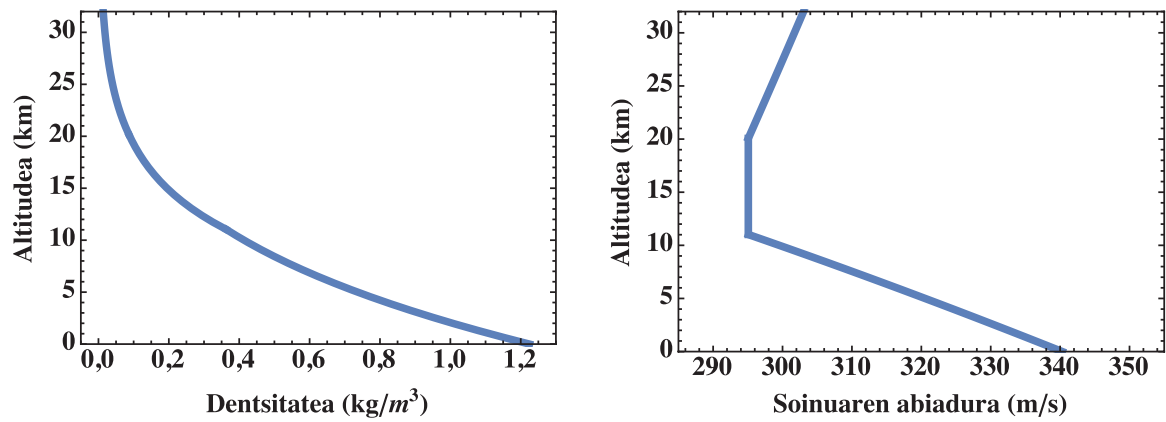

10. irudia. Airearen dentsitatea (ezkerraldean) eta soinuaren abiadura atmosferan zehar.

Optimizazio-problemaren soluzioa 9. irudian ikus daiteke. EO zuzendua erabili dugu ABE ekuazioaren soluzioa hurbiltzeko. Adjuntuan oinarrituriko jaiste-metodoaren 100 iterazioren ondoren, lortutako hasierako datuak nahiko ondo hurbiltzen du helburua. Biskositatea dela eta, oszilazio txikiak agertu dira, baina EO erabiliz bere efektua murriztea lortu dugu. Gainera, pauso txikiak emanez, malda handiko guneen eragina ere saihestu dugu.

\section{AIPAMENAK}

Nire eskerrak Enrique Zuazuari lana burutzeko emandako gida eta aholkuengatik; baita ikerketan parte hartu zuten kolaboratzaileei ere, bere- 
ziki Liviu Ignati, Navid Allahverdiri eta Francisco Palaciosi. Tesia BCAM ikerketarako zentroan burutu zen, Eusko Jaurlaritzaren Hezkuntza, Hizkuntza Politika eta Kultura Sailaren doktoretza-aurreko programaren bidez finantzaturik.

\section{ERREFERENTZIAK}

[1] POZO A. 2014. Large-time behavior of some numerical schemes: application to the sonic-boom phenomenon. Doktorego tesia, Euskal Herriko Unibertsitatea.

[2] PAWLOWSKI J.W., GRAHAM D.H., BOCCADORO C.H., COEN P.G. eta MAGLIERI D.J. 2005. «Origins and overview of the Shaped Sonic Boom Demonstration program». AIAA technical report 2005-5, AIAA (USA).

[3] ALONSO J.J. eta COLONNO M.R. 2012. «Multidisciplinary optimization with applications to sonic-boom minimization». Annual Review of Fluid Mechanics, 44, 505-526.

[4] RALLABHANDI S.K. 2011. «Advanced sonic boom prediction using augmented Burger's equation». Journal of Aircraft, 48, 1245-1253.

[5] RALLABHANDI S.K. 2011. «Sonic boom adjoint methodology and its applications». 29th AIAA Applied Aerodynamics Conference, AIAA (USA).

[6] CLEVELAND R.O. 1995. Propagation of sonic booms through a real, stratified atmosphere. Doktorego tesia, University of Texas at Austin (USA).

[7] MINELLI A., SALAH EL DIN I. eta CARRIER G. 2012. «Advanced optimization approach for supersonic low-boom design». 18th AIAA/CEAS Aeroacoustics Conference (33rd AIAA Aeroacoustics Conference), AIAA (USA).

[8] BURGERS J.M. 1940. «Application of a model system to illustrate some points of the statistical theory of free turbulence». Proceedings of the Royal Netherlands Academy of Sciences, 43, 2-12.

[9] LIGHTHILL M.J. 1956. «Viscosity effects in sound waves of finite amplitude». Surveys in Mechanics, Cambridge University Press, 250-351.

[10] CARLTON T.W. eta BLACKSTOCK D.T. 1974 «Propagation of plane waves of finite amplitude in inhomogeneous media with applications to vertical propagation in the ocean». ARL-TR-74-31, Applied Research Laboratories, The University of Texas at Austin (USA).

[11] FRIDMAN V.E. 1976 «Propagation of a strong sound wave in a plane layered medium». Soviet Physics - Acoustics, 22, 349-350.

[12] PIERCE A.D. 1989. Acoustics: an introduction to its physical principles and applications. Acoustical Society of America (USA).

[13] GODLEWSKI E. eta RAVIART P.-A. 1991. Hyperbolic systems of conservation laws. Mathematiques \& Applications 3, Ellipses (France). 
[14] LEVEQUE R.J. 2004. Finite-volume methods for hyperbolic problems. Cambridge Texts in Applied Mathematics, Cambridge University Press (UK).

[15] IGNAT L.I. eta POZO A. 2017. «A semi-discrete large-time behavior preserving scheme for the augmented Burgers equation». ESAIM: Mathematical Modelling and Numerical Analysis, DOI: 10.1051/m2an/2017029.

[16] LIU T.P. eta PIERRE M. 1984. «Source-solutions and asymptotic behavior in conservation laws». Journal of Differential Equations, 51, 419-441.

[17] KIM Y.J. eta TZAVARAS A.E. 2001. «Diffusive N-waves and metastability in the Burgers equation». SIAM Journal on Mathematical Analysis, 33, 607633.

[18] IGNAT. L.I., POZO A. eta ZUAZUA E. 2015. «Large-time asymptotics, vanishing viscosity and numerics for 1-D scalar conservation laws». Mathematics of Computation, 84, 11633-1662.

[19] ALLAHVERDI N., POZO A. eta ZUAZUA E. 2016. «Numerical aspects of large-time optimal control of Burgers equation». ESAIM: Mathematical Modelling and Numerical Analysis, 50, 1371-1401.

[20] ALLAHVERDI N., POZO A. eta ZUAZUA E. 2016. «Numerical aspects of sonic-boom minimization». A Panorama of Mathematics: Pure and Applied, Contemporary Mathematics 658, American Mathematical Society, 267-279. 